\title{
Teaching Arabic Machine Translation to EFL Student Translators: A Case Study of Omani Translation Undergraduates
}

\author{
Yasser Muhammad Naguib Sabtan ${ }^{1,2}$ \\ ${ }^{1}$ Department of English Language and Literature, College of Arts and Applied Sciences, Dhofar University, \\ Salalah, Oman \\ ${ }^{2}$ Department of English, Faculty of Languages and Translation, Al-Azhar University, Cairo, Egypt \\ Correspondence: Yasser Muhammad Naguib Sabtan, College of Arts and Applied Sciences, Dhofar University, \\ Salalah, PO Box: 2509, Postal Code: 211, Oman. E-mail: ysabtan@du.edu.om
}

Received: December 23, 2019 Accepted: January 24, 2020 Online Published: February 5, 2020

doi:10.5539/ijel.v10n2p184 URL: https://doi.org/10.5539/ijel.v10n2p184

\begin{abstract}
The present paper describes a machine translation (MT) course taught to undergraduate students in the Department of English Language and Literature at Dhofar University in Oman. The course is one of the major requirements for BA in Translation. Fifteen EFL translation students who were in their third year of study were enrolled in the course. The author presents both the theoretical and practical parts of the course. In the theoretical part, the topics covered in the course are outlined. As for the practical part, it focuses on the translation students' post-editing of online MT output. This is beneficial to the students as free online MT systems can potentially be used as a means for improving student translators' training and EFL learning. This is achieved through subjecting MT output to analysis or post-editing by the students so that they can focus on the differences between the source and target languages. With this goal in mind, assignments were given to the students to post-edit the Arabic and English MT output of three free online MT systems (Systran, Babylon and Google Translate), discuss the linguistic problems that they spot for each system and choose the one that has the fewest number of errors. The results show that the students, with varying degrees of success, have managed to identify some linguistic errors with the MT output for each MT system and thus produced a better human translation. The paper concludes that there is a need to incorporate MT courses in translation departments in the Arab world, as integrating technology into translation curricula will have great effect on student translators' training for their future career as professional translators.
\end{abstract}

Keywords: Arabic machine translation (MT), EFL student translators, free online MT systems, MT evaluation, post-editing, Omani undergraduates, teaching MT

\section{Introduction}

Machine Translation (MT), which refers to the attempt to automate the process of translating text or speech from one language to another (Arnold et al., 1994), has become a main technology in the current age of information technology. As the demand for translation has increased tremendously, MT is now widely used around the world (Almutawa \& Izwaini, 2015). Human translators cannot cope with the large amount of the materials that are needed to be translated in every field. They, thus, can use MT to help them meet such demands, as MT systems can save them time and efforts. MT systems can be used to provide rough translations that could be then post-edited by translators to produce an accurate translation.

Due to the important role that MT plays in the translation profession, many universities throughout the world have introduced MT as one of the main courses for both postgraduate and undergraduate students majoring in translation. As far as the Omani context is concerned, Dhofar University (DU) BA in Translation program contains an MT course as one of the major courses of a student's plan of study. The author of the current paper taught this course to translation major students in the spring semester of the academic year 2018-2019. During the course students were introduced to the MT technology, with a focus on different MT-related topics such as historical background, main approaches (rule-based vs. statistical), tools for language processing, linguistic challenges for Arabic MT and post-editing and evaluation of MT output.

In this paper the author reports on his experience of teaching this course to fifteen translation students at DU in 
Oman. The course is composed of two parts; the first is a theoretical part and the other one is a practical part. Some MT-related topics are covered in the theoretical part. In the practical part of the course the students were assigned a task to evaluate and then post-edit the MT output of some free online MT systems. This can be beneficial to students' development of their translation skills as free online MT systems can potentially be used as a tool for improving student translators' EFL learning and translation training. This is achieved through exposing translation students to online MT systems. The pedagogical reasoning behind this, as emphasized by Somers (2001), is that it makes the students focus on the differences between the source language (SL) and target language (TL) and identify the processes by which a given meaning in the SL is conveyed to the TL. In this context, the students were asked to post-edit the MT output for some Arabic and English texts. In this framework they were also asked to carry out a comparative evaluation of the translation output of three MT systems through discussing the linguistic errors made by each MT system and choose the system that has the fewest number of errors and thus the best translation output. The MT systems that are used to translate the texts under study are Google Translate (Note 1), Babylon (Note 2) and Systran (Note 3). As pointed out by Somers and Wild (2000), comparative evaluation of different MT systems that translate the same content may be particularly revealing. In fact, at the end of the theoretical part of the MT course the students appreciated the difficulties faced by MT systems and thus they could spot a number of errors in the performance of the three MT systems under analysis. Drawing on the results of the students' remarks about the MT output, the paper concludes that introducing MT courses to translation students as well as integrating the use of free online MT systems into such courses can be very useful for the students' foreign language learning and translation training.

The remainder of the paper proceeds as follows: in section 2 the objectives of the study are outlined. Section 3 presents the research questions of the study. A review of the literature covering the types of MT and previous studies on the use and teaching of MT is discussed in section 4 . Then section 5 provides an overview of the topics that are covered in the course, and the practical exercises. Section 6 presents the methods used in the present study. Section 7 discusses the results of students' post-editing of MT output. Finally, a conclusion of the paper is presented in section 8 .

\section{Objectives of the Study}

The current study aims to describe an MT course taught to undergraduate translation students in the Department of English Language and Literature (ELL) at DU in Oman. Within this framework the study sheds light on the students' evaluation of the translation of some online MT systems as this could have didactic purposes such as improving students' EFL learning and translation training. Accordingly, students were asked to evaluate and post-edit the output of three MT systems, classify the linguistic errors that they spot for each one of these systems and choose the system that produces the best translation.

\section{Research Questions}

The current study aims to answer the following research questions:

a) Are Omani EFL translation students able to spot MT errors?

b) How far can they classify the types of MT errors?

c) Are they able to give the right equivalents for wrong MT translations?

\section{Literature Review}

MT, which is a subfield of the broader area of computational linguistics, generally refers to the process by which a computer software is used to translate text or speech from one human language (such as English) to another (such as Arabic). MT has been traditionally classified into two major types, namely rule-based and corpus-based. In rule-based MT three types can be distinguished, i.e., direct, interlingua and transfer (Hutchins \& Somers, 1992; Somers, 2003). Direct MT systems are based on finding direct equivalents between SL and TL words. It is a word-by-word approach to translation, with a few grammatical rules for reordering of words in the TL. As for transfer and interlingua types, they use grammatical rules generally hand-written by linguists and bilingual dictionaries to create translations. Transfer-based systems analyze the structure of SL sentence and then transfer its grammatical structure to the TL. In Interlingua the SL sentence to be translated is transformed into an artificial formal language, i.e., the interlingua, and then the TL sentence is generated from the interlingua. In this approach the interlingua is basically an abstract language independent meaning representation which can be used to generate the TL (Jurafsky \& Martin, 2009). Corpus-based MT systems (statistical and example-based), on the other hand, are based on the so-called data-driven approach which is a new paradigm in which a bilingual parallel corpus of SL texts along with their translations into the TL is used as a model to the MT system on which it could base its new translation (Somers \& Diaz, 2004). Some MT systems have used a hybrid approach, 
combining the features of both rule-based and corpus-based techniques (Okpor, 2014). However, since about 2013 a few MT systems have started to use a new approach called 'neural machine translation' (NMT), which is a major recent development in MT. Neural networks are statistical models that were first used in speech technology. NMT is a new breed of corpus-based MT and it is similar to statistical MT as it is trained on large parallel corpora but uses a different approach, i.e., neural networks. This promising approach is now the state of the art in MT as it has become the preferred paradigm in the field (Forcada, 2017). Google Translate, for instance, which supports more than 55 different languages according to Alqudsi et al. (2014), currently uses NMT approach (Wu et al., 2016; Johnson et al., 2017). Likewise, Systran MT system has shifted to NMT as discussed by Crego et al. (2016).

Many studies have been conducted on MT and translation technologies in general, but only a small number of such studies relate to the topic of teaching MT to undergraduate and/or postgraduate students. Somers (2001) throws light on the role of MT in curricula for three different types of students: student translators, foreign-language learners and students majoring in computational linguistics. He points out that the three different groups of students have different interests and needs. Gaspari (2001) conducts a survey for thirty-eight translation students who took MT courses. The survey was carried out asking the participants of the study to respond to a number of questions that aimed to assess the respondents' knowledge and opinions about MT. Kenny and Way (2001) make a contrastive study of teaching an undergraduate MT course to applied computational linguistics (ACL) students and Computer-Assisted Translation (CAT) course to translation students in undergraduate as well as postgraduate levels. These two sets of students, which the authors distinguish as 'developers' (for ACL students) versus 'users' (for translation students), have different backgrounds and so the course material, methods of teaching and assessment all differ. Clavier and Poudat (2001) report on their experience of teaching MT to students whose major is not computer science at the University of Orleans. They point out that in French universities MT is often taught within the framework of language and linguistics courses at Departments of foreign language and linguistics rather than departments of computer science. Belam (2002) discusses the use of a self-study project on MT evaluation as part of an MT course taught to final-year undergraduates. The usefulness of studying MT evaluation has been emphasized in the study, as it has shown that it is very beneficial to students' language learning. In the same vein the current study stresses the same idea of using MT evaluation as a valuable tool that helps students in their EFL learning. Mitamura et al. (2003) describe a graduate-level MT course which is taught to M.S. and Ph.D. students at Carnegie Mellon University. The students enrolled in the MT course have a background in linguistics or computer science. The goal of the course is primarily technical, as it teaches the students how to build or develop MT systems. In Jolley and Maimone's study (2015) the use and perceptions of free online MT by Spanish students and instructors are investigated. Their study is based on a survey that addresses the participants' use of and attitudes about free online MT systems. In conclusion of their study they show that nearly all students used free online MT systems and the majority of instructors employed free online MT systems, especially Google Translate, for personal or teaching purposes. Bakaric (2019) argues for integrating post-editing and MT content into a CAT course and proposes the course content which she demands to be mandatory for all foreign language students.

Some other studies focus mainly on discussing the specific topic of MT evaluation and post-editing. As Allen (2003) notes, post-editing is the correction of texts that have been translated from an SL into a TL by an MT system. O'Brien (2002) argues for the need of teaching post-editing in translator training courses. She proposes a course content in post-editing and lists a set of skills that are required of a post-editor. These skills include general knowledge of MT technology, skills on handling terminology, and skills in programming as well as text linguistics. Before having these special skills, a potential post-editor, as maintained by O'Brien (2002), should have acquired general skills such as basic linguistics and translation skills, IT skills, and an introduction to language technology with a focus on translation memory (TM) tools, and knowledge of SL and TL. Garcia (2011) conducts a study in which he carries out an experiment on two groups of English-Chinese trainee translators, where one group translated texts from the SL (which he calls the control group) and the other one post-edited a machine-translated text (which he calls the experimental group). The results of his study show that post-editing produces significantly better results when compared to translating from scratch with regard to the quality of translated texts. However, as far as productivity is concerned, the study shows marginal gains in that aspect. More recently, Koponen (2015) throws light on an MT and post-editing course taught in 2014 at the University of Helsinki in Finland. She discusses the experiences of teaching the post-editing course, covering both the theoretical and practical aspects. The topics discussed include the technical principles of MT as well as post-editing practice and MT evaluation. In a later study, Koponen (2016) presents an overview of the use of MT post-editing as a central practice in the field of translation and discusses post-editing productivity and efforts. She states that post-editing MT can increase the productivity of professional translators compared to manual 
translation from scratch.

Another line of research in MT is concerned with investigating the use of MT for language learning. Anderson (1995) argues that despite their poor performance, online MT systems can be used as a tool to improve foreign language learning. Niño (2009) investigates the relationship between MT and foreign language learning and outlines some of the implications of the use of free online MT systems as a language tool for foreign language learning. In this respect, he presents some of the advantages of using MT in the classroom. One of the pedagogical methods he used (among other methods) is called 'MT as a bad model'. This model forces the learner to identify errors and inconsistencies in the translation of MT output and he can thus have a better understanding of the language. This idea is also embraced by the present study which argues that exposing student translators to MT output can be advantageous for their EFL learning and development of their translation skills. Clifford et al. (2013) discuss the role of MT in language learning. They discuss the results of a survey among undergraduate students at Duke University in the USA about their use of MT at foreign language courses (e.g., French, Italian, Spanish and Portuguese). They also survey the perceptions of MT among foreign language instructors. They report that the students see MT as a helpful tool in their language learning, especially in acquisition of vocabulary, but at the same time they are aware that MT produces errors. Instructors, on the other hand, see that MT is more useful in advanced-level courses. In a more recent study, Jimenez-Cresp (2017) sheds light on the role of translation technologies, including MT, in Spanish language learning, focusing on its role as a helping tool in the tasks of reading and writing as well as the use of post-editing for language learning. In another context in Indonesia, Anggrina et al. (2017) investigate how EFL learners used post-editing to revise the MT output produced by Google Translate in English-Indonesian language pair. They point out that the participants of the study, who are 20 EFL learners, were able to correct the linguistic errors in the MT output.

As far as the Arabic context is concerned, the studies conducted on online MT systems in the Arabic/English language pair focus mainly on evaluating the output of such MT systems by the researchers themselves or investigating the students' attitudes towards the use of these systems. No studies, to the best of our knowledge, have been carried out on assessing the EFL translation students' post-editing of the output of MT systems. Izwaini (2006), for instance, conducts a study to diagnose the Arabic MT problems in three MT systems (Google, Sakhr and Systran). Moreover, he analyzes the MT flaws, attempting to find out the reasons for such problems and suggests solutions to them. Almutawa and Izwaini (2015) investigate how widely MT is used in the Arab world by taking Saudi Arabia as a case study. This is carried out through a survey to Saudi organizations to assess the number of Arabic MT systems that are used by these organizations. They also carry out another survey designed for Saudi higher education institutions to find out if universities and research centres are interested in MT with respect to teaching and researching in MT. The study concludes that most Saudi organizations and translation agencies have little interest in MT and only a few universities have conducted research in this area. In conclusion, the study recommends that more attention to MT be paid by Saudi organizations, translation agencies and universities. It is also recommended that more research be conducted by universities and research centres which, in turn, will contribute to the improvement of the currently used Arabic MT systems so as to get the most use of the MT technology. In another line of research Alhaisoni and Alhaysoni (2017) explore the Saudi EFL university students' attitudes towards the use of the multilingual system Google Translate. The study was conducted through using a questionnaire that was distributed to the students. The study shows that Google Translate was used by almost all the participants in the study for various purposes, including vocabulary, writing, reading and translation. The mostly used purpose was to get the meaning of unknown words. More recently, in a qualitative study Jabak (2019) assesses Arabic-English translation produced by Google Translate through conducting an error analysis of some Arabic samples translated by Google Translate into English. The researcher shows that the MT output of Google Translate includes lexical and syntactic errors which affect the quality of translation. In fact, as pointed out by Sabtan $(2016,2019)$, Arabic is challenging for MT as it is known for being a free word order language with a morphologically complex system. In another recent study Alsalem (2019) indicates that post-editing of Google Translate output is beneficial to student translators' development of their translation skills. However, she warns against using it at the beginning stage of translation training. This conclusion is also supported by the current study, as it sees that post-editing of MT output is beneficial to student translators' training at an advanced stage of their study (i.e., the third and fourth years of study).

\section{Course Description}

The ELL Department is one of the departments in the College of Arts and Applied Sciences at DU. It offers a major in translation at the undergraduate level. Besides studying different courses including Arabic and English, translation students have to study several translation and linguistics courses to complete a BA in Translation. MT is one of the translation courses that translation major students take as part of their major requirements. The MT 
course was offered in the spring semester for the academic year 2018-2019. Fifteen EFL students, all of them are native speakers of Arabic, were enrolled in the class. All the students, who were in their third year of study, had no background in computational linguistics. The course is 3-hour credit and is taught over 18 weeks in a computer lab. The following subsections describe the course objectives and topics, and the practical exercises.

\subsection{Course Objectives and Topics}

The course on MT aims to introduce students to the field of MT and focuses on the difference between machine translation and human translation. It combines both theoretical background and practical exercises. The course reading materials contain a number of chapters from various textbooks and published papers. Main concepts of MT are taken from Arnold et al. (1994). A brief history of MT is taken from Hutchins (1986). Jurafsky and Martin (2000) book is used for reading on the natural language processing (NLP) tools that are essential for MT. As for discussing MT evaluation and post-editing, related chapters are taken from Hutchins and Somers (1992) and Trujillo (1999). In addition, students were provided with relevant websites and conference proceedings. The topics covered in the course include the following:

Introduction to MT: What is MT? the difference between MT and human translation as well as the difference between MT and other technologically-assisted translation tools such as CAT and TM.

Overview of MT history: In this part different periods of MT history have been explored. These include the pioneers (1933-1956), with a focus on Warren Weaver's 1949 memorandum, the decade of optimism or high expectation and disillusion (1956-1966), along with highlighting the Automatic Language Processing Advisory Committee (ALPAC) report and its consequences which brought an end to research on MT in the United States. In the following decade (1967-1976) research on MT was largely conducted outside the United States. It was carried out in Canada and Western Europe. Then the commercial systems emerged in the following decade (1976-1989) such as the English-French Meteo system for translating weather reports. Finally, research on rule-based and corpus-based MT since 1989 to the present has been discussed.

Main approaches to MT: Rule-based MT (direct, interlingua and transfer), Corpus-based (example-based MT and statistical MT) and hybrid approaches that combine the features of both rule-based and corpus-based approaches.

Translation problems: Various linguistic problems that face MT are discussed, including ambiguity issues (lexical ambiguity and structural ambiguity), as well as the challenge of translating multiword units (idioms and collocations).

NLP tools: These include Part-of-Speech (POS) tagging, Syntactic Parsing and Word Sense Disambiguation (WSD).

MT evaluation \& post-editing: Students had some lectures outlining the main concepts and principles and are referred to additional readings (Allen, 2003; White, 2003). In the practical part of the course the students were asked to evaluate three online bidirectional MT systems through a few assignments. These systems are Google Translate, Systran and Babylon. They were, consequently, asked to choose the best translation system and then post-edit the MT translation of that system.

\subsection{Course Assignments}

As pointed out above, the course is composed of a theoretical part and a practical part. The theoretical part in which a number of MT topics have been discussed was supplemented with homework assignments involving evaluating and post-editing the MT output of three MT systems (Systran, Babylon and Google Translate). The languages used in the assignments are English and Arabic. The students were asked to perform a comparative evaluation of the output of the three MT systems through carrying out the following:

a. Discuss the linguistic problems in the translation for each MT system and choose the best translation output.

b. Post-edit the translation of the best system to give an accurate rendering of the SL text into the TL text.

It should be noted that full-scale MT evaluation, as pointed out by Belam (2002), is certainly a specialized field which is beyond the scope of a one-semester course. Students are not actually expected to do large-scale research into the field itself, but they have a number of lectures outlining the basic concepts and principles based on related chapters from Hutchins and Somers (1992) and Trujillo (1999) and they are advised to read some related references such as Allen (2003). Consequently, within the limited scope of their evaluation assignments, it is unlikely that they will reach practically useful conclusions about any of the three MT systems under investigation. However, according to Belam (2002), including a part about post-editing and evaluation in the MT 
course is beneficial in several ways. First, it is likely that translation students will be expected to think of using MT systems in their future career as professional translators. Thus, studying MT evaluation in this way will help them have a good knowledge of MT problems and thus can easily answer MT-related questions such as "Is MT any good?", "Can MT save us money and effort?", "Which system produces the best translation output among a number of MT systems?" Second, evaluation of MT output requires the student translators to take into consideration other topics discussed in the course. Therefore, they are required to detect the linguistic errors in the outputs of the MT systems and could easily relate these to the topics discussed about the challenges facing MT (e.g., lexical and structural ambiguity problems) and could also have an idea about the possible NLP tools that are used to solve such problems. Third, this exercise of MT evaluation lets students consider their first impressions and preconceptions of MT which, according to Gaspari (2001), may vary. Some students find it particularly useful in translating material online, and thus overestimate its capabilities. Other students, on the other hand, tend to distrust the raw MT output when they compare it with the human translation that is required by their concurrent translation courses. In fact, students should know the purpose of the translation and the audience it targets.

\section{Methods}

The research methods that are used in the current study are presented in this section.

\subsection{The Study Procedures}

The present study is qualitative in nature, and so the researcher used the descriptive analytical approach through investigating the following:

1) The ability of Omani translation students to spot the errors in the output of different MT systems.

2) The extent to which they can classify the types of MT errors and suggest the right equivalents.

\subsection{The Participants}

Fifteen translation students (all of them females) participated in the present study. The students who were EFL students majoring in translation were enrolled in the MT course offered at DU in Oman. The participants, who are also native Arabic speakers, were given two texts translated by three different online MT systems and were asked to identify the errors produced by each one of the three MT systems under study, classify the type of error and then choose the best MT system among the three and post-edit it to produce a final intelligible translation.

\subsection{The Data}

The students were given as home assignments two texts translated by three online MT systems, i.e., Systran, Babylon and Google Translate. The first text is an English scientific text taken from a website called the Translators Avenue (Note 4). The website includes a number of general and specialized English texts along with their Arabic translations. The second text is an Arabic consumer-oriented text taken from Dickins et al. (2002) book Thinking Arabic Translation. Both texts have been translated by the three online MT systems under investigation.

It should be noted that some of the linguistic problems that face the online MT systems under analysis have now been addressed; as such systems continuously improve their MT. For instance, in Systran MT system it has been recently observed that some linguistic errors made by this system have now been addressed after applying the Neural MT, as declared on Systran's website and as also discussed in Crego et al. (2016).

The most important issue here is the students' endeavours in dealing with the MT-produced texts and spotting their errors as this is expected to have beneficial consequences for their EFL learning and translation training. In the following section, the MT translation of the three systems under study will be discussed along with students' remarks about the different linguistic problems in their output. The first part deals with English-Arabic translation mode, while the second part is dedicated to Arabic-English translation mode.

\section{Analysis and Discussion}

The analysis of the students' homework assignments will be discussed below. Students succeeded in spotting a number of errors in the output of the three MT systems under investigation. Error analysis, according to Stymne and Ahrenberg (2012), is a means to assess MT output in qualitative terms. In particular, it refers to the identification and classification of individual errors in a text translated by an MT system. This section discusses some of the MT errors that were identified by the students in both English-Arabic translation and Arabic-English translation. 


\subsection{English-Arabic Translation}

This part discusses the MT from English into Arabic. In this mode, students managed to spot a number of linguistic problems that face the three online MT systems (Systran, Babylon and Google Translate). In the following lines the researcher gives some examples for the errors that were identified by the translation students for English-Arabic MT produced by the three MT systems. The students classified such errors into different linguistic types and suggested the right translation equivalents.

\section{Example 1:}

The chief figure of the scientific revolution of the seventeenth century was Sir Isaac Newton.

$$
\begin{aligned}
& \text { Systran } \\
& \text { Sabylon } \\
& \text { Soogle Translate }
\end{aligned}
$$

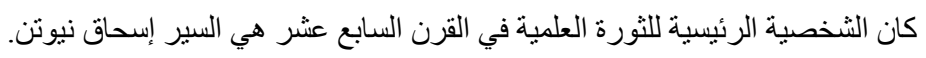

Students managed to spot a few errors in the output of the three MT systems. In fact, $78.6 \%$ of students were able to spot that there is a lexical error in the translation of the word "figure", as they identified that the English word "figure" has multiple meanings (i.e., polysemous). It may mean "رخخصية" which is the right meaning in the current example. Babylon and Systran have given wrong translations of the word "figure" while Google Translate has given the right equivalent. They also identified that the translation of Google Translate includes a grammatical error which is the wrong use of the masculine form "كان" instead of the feminine form "كانت" to be in agreement with the word "النخخصية". This error was spotted by $71.5 \%$ of the students in the current study. A better translation could be "يعد السير إسحاق نيوتن العلم الأبرز من بين أعلام الثثرة العلمية في القرن السابع عشر"

\section{Example 2:}

He was a physicist and mathematician who laid the foundations of calculus.

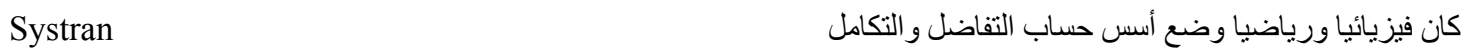

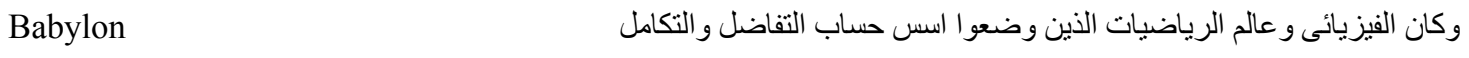

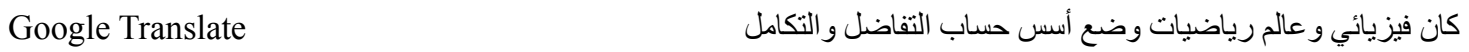

The biggest number of students (93\%) managed to spot that there is a grammatical error in the translation of Babylon MT system for using the plural form of the phrase " "الذين وضعو" instead of the singular form which is the correct form since the subject is singular. But Systran and Google have used the correct singular form. The error has been made by Babylon MT system because it considered the two nouns "physicist and mathematician" as describing two persons, and they are describing one person, namely Isaac Newton. It should be noted that Google Translate used the noun "فيزيائي" after the copula verb "كان" in the nominative case while it must be in the accusative case because it is the predicate here and the subject, which is always in the nominative case after "كان" (Ryding, 2005), is an elliptic pronoun (a pro-drop in Arabic) referring to Isaac Newton in the previous sentence. Systran has correctly rendered the word into Arabic in the accusative case "فيزيائيا". However, this error was not spotted by the students, and since it is a case marking error it will not be considered among the list of errors. A better translation could be "فهذا الفيزيائي والرياضي هو من أرسى قو اعد علم التفاضل و التكامل"

\section{Example 3:}

He discovered the law of gravitation.

Systran

$$
\text { فاكتثتف القانون الجاذبية. }
$$$$
\text { Babylon }
$$

Google Translate

In Systran MT output the verb "يكتشف" is used in the present tense instead of the past tense. Also, the definite article "الال" is wrongly used in the first noun "قانون" of a construct phrase (الإضافة) in Arabic. In a construct phrase (also called "possessive construct") the first noun is always in the indefinite case and the second noun is in the definite case. This grammatical error was identified by $78.6 \%$ of the participants in the study. Babylon MT system has wrongly deleted the definite article "الجاذبية" "الج". As for Google Translate, it has 
managed to render the SL sentence correctly into the TL sentence

Having reviewed some of the linguistic problems in the English-Arabic MT of all the three systems, the students chose the output of Google Translate as the best one, showing that it has fewer errors than the other two systems.

Table 1 below lists the English-Arabic translation errors that were identified by the students for each MT system as well as their linguistic types. Moreover, the table includes the percentage of students who managed to spot the same type of error. This indicates the translation problems that are commonly recognized by the participants of the study.

Table 1. Students' error analysis of English- Arabic MT

\begin{tabular}{|c|c|c|c|}
\hline MT System & Error & Type of Error & Students' Identification of Errors (\%) \\
\hline \multirow[t]{3}{*}{ Systran } & 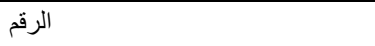 & lexical & $78.6 \%$ \\
\hline & يكتشف & grammatical & $78.6 \%$ \\
\hline & إضافة أداة التعريف (ال) في كلمة قانون & grammatical & $78.6 \%$ \\
\hline \multirow[t]{3}{*}{ Babylon } & 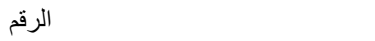 & lexical & $78.6 \%$ \\
\hline & الذين وضعو ا & grammatical & $93 \%$ \\
\hline & حذف أداة التعريف (ال) من كلمة الجاذبية & grammatical & $78.6 \%$ \\
\hline Google Translate & 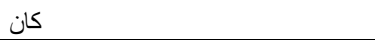 & grammatical & $71.5 \%$ \\
\hline
\end{tabular}

It is obvious that the students, with varying degrees of success, were able to spot a number of errors in the MT output of the three systems under investigation.

The following figure compares between the three MT systems with regard to the frequency of errors that were identified by the students in English-Arabic translation as shown in table 1. The errors listed in the table are seven errors, where each of Systran and Babylon made three errors out of the total seven $(42.85 \%)$ and Google Translate made only one error (14.28\%). Also, in the examples discussed it is obvious that the grammatical errors (five out of seven) are more than the lexical errors (two out of seven) in English-Arabic translation mode.

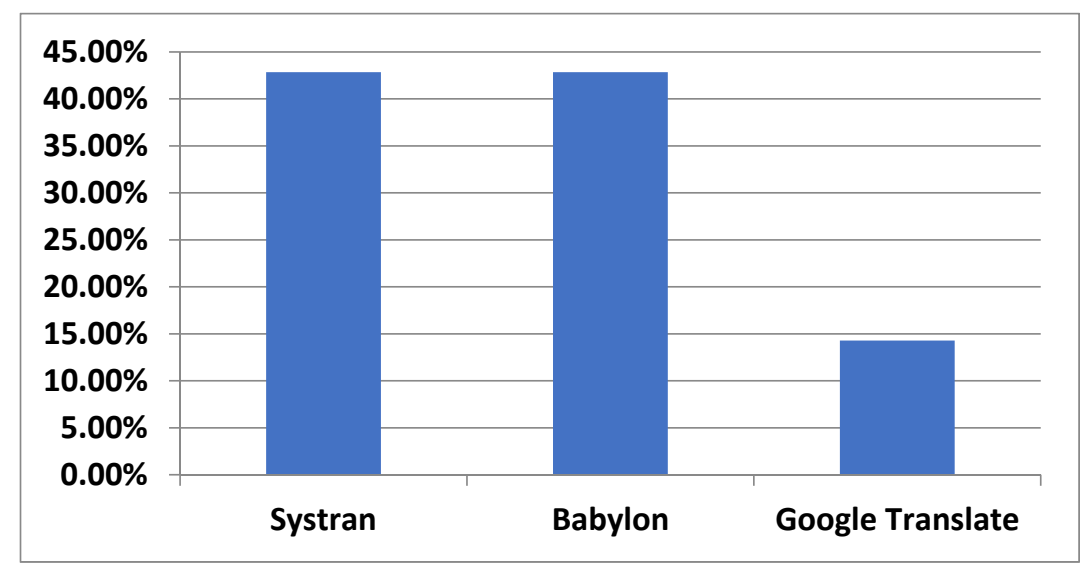

Figure 1. Comparison of frequency of errors in the three MT systems for English-Arabic translation

It goes without saying that students' identification of the previous errors helps them to know the different types of translation problems that face MT and this leads them to overcome such problems when they give their final human translation. Also, this helps them understand the SL (Arabic) and TL (English) in this direction of translation.

\subsection{Arabic-English Translation}

This section discusses the MT from Arabic as an SL into English as a TL. Students managed to identify a number of linguistic errors in the output of the three MT systems and suggest the right equivalents. The following examples shed light on the problems that were identified by the students in the current study. 


\section{Example 4:}

إن كانت مدينة فاس تفخر بأثنياء تميز تاريخها وحضارتها، فإنها تفخر على وجه الخصوص بعلاقتها بالمؤرخ وعالم الاجتماع العربي الثهير،

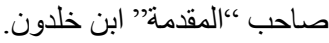

Systran If the city of Fez boasts things that distinguish its history and civilization, it is particularly proud of its relationship with the historian and the famous Arab sociologist, the owner of the "Introduction" Ibn Khaldun.

Babylon The Fez is proud of its history and civilization, things distinguish it is proud of, in particular, its relationship met with historian and world famous Arab meeting, the owner of the \&'provided\&'; Ibn Khaldoun.

Google If the city of Fez is proud of things that distinguish its history and civilization, it is Translate particularly proud of its relationship with the famous Arab historian and sociologist, the owner of the "introduction" Ibn Khaldun.

The students pointed out that there is a lexical ambiguity problem with the word "صاحب" which is translated by the three MT systems as "owner". All the participants (100\%) managed to identify that it is the wrong equivalent. They suggested the right equivalent to be "author" or "writer". The Arabic word "صاحب" is a polysemous word which can mean "friend", "owner" or "author/writer"; where the last sense is the one meant in the current context. As a matter of fact, all the students managed to spot that the translation is wrong but $93 \%$ of them were able to specify that there is a lexical ambiguity problem in that example and rendered the word as "author" or "writer". Even some of them indicated that the solution lies in the application of WSD technique to solve this problem.

In fact, there is a structural problem in Systran MT which was identified by $78.6 \%$ of the students in the current study. It is the wrong order of the word "famous". The right order of the translation should be as that of Google Translate "the famous Arab historian and sociologist".

As for Babylon MT, students have shown that there are also some other linguistic problems in its output. The translation contains some structural problems. For example, "things distinguish it is proud of" is the wrong structure of the sentence. All the students in the study $(100 \%)$ identified this wrong structure. Also, there are some problems in terms of lexemes. For example, "met" and "meeting" are wrong choices of lexemes as well as the translation of مقدمة as 'provided'. These problems were identified by $93 \%$ of the participants of the study. It should be noted that the word "meeting" was wrongly produced by Babylon because the compound word " الاجتماع" was translated word-for-word as "world" and "meeting". The system wrongly interpreted the first word as meaning "world" and not "scientist" while it means "sociologist" as found in Systran and Google outputs.

The definite article "the" is wrongly used before the noun "Fez" in the output of Babylon MT system. In fact, the definite article is used before some proper nouns such as the name of countries like "the Netherlands", "the United States" and "the United Kingdom" but the Moroccan city "Fez" is used without the definite article. This grammatical error was detected by $93 \%$ of the participants in the study.

Also, the word "مقدمة" was translated as "introduction" by the three MT systems. Normally, the name of the book is transliterated as "Muqaddimah". In fact, one of the fifteen students rendered it in the transliterated form. However, it will not be considered an error as the English word "introduction" or "Prolegomena" are sometimes used to refer to Ibn Khaldun's book.

\section{Example 5:}

$$
\text { كما أنها تفخر بكونها موطن جامعة القرويين، أقدم الجامعات في العالم. }
$$

Systran It is also proud to be home to the Villagers' University, the world's oldest university.

Babylon It is proud to be the home of the University of villagers, the oldest universities in the world.

Google It is also proud to be home to the University of Karaouine, the oldest university in the Translate world.

Both Systran and Babylon MT systems translated the proper noun "القرويين" as "villagers" since the proper noun is similar to the plural of the lexical item "قروي" meaning "a villager". Google Translate, on the other hand, translated the proper noun correctly and thus rendered the full name as "University of Karaouine". This error in Systran and Babylon outputs was identified by $78.6 \%$ of the students who gave the right equivalent. As for the second part of the sentence "قالجدم الجامعات في العالم", Babylon translation "the oldest universities in the world" is grammatically wrong. Babylon system uses the plural form "universities" to refer to one university which is 
“"جامعة القرويين". However, this error was identified by only 21.5\% of students.

\section{Example 6:}

$$
\text { وتثهد أيامها المتعاقبة، وفصولها المختلفة احتفالات ومهرجانات متنو عة. }
$$

Systran Successive days and different seasons are witnessing various festivals and celebrations.

Babylon Successive days, witnesses various celebrations of various festivals and classrooms.

Google Its successive days and various seasons witness various celebrations and festivals.

Translate

The word "فصول" was wrongly translated as "classrooms" by Babylon MT system. But Systran and Google Translate have given the right equivalent "seasons". In fact, the Arabic word "فصل" is polysemous, as it has multiple meanings. It can mean "season" (which is the right equivalent in the current example), "classroom" which was wrongly chosen by the Babylon MT system as the English equivalent or "chapter". This lexical error was identified by $78.6 \%$ of students who suggested "seasons" as the right equivalent. Moreover, the structure of the sentence in Babylon translation is ill-formed, where the word order is wrong. Notably, $85.7 \%$ of students in the study identified this structural error. An error which was spotted by $93 \%$ of students is the missing possessive pronoun "its" in Systran and Babylon MT outputs. Google, on the other hand, did not miss the pronoun as shown above.

The following table lists the Arabic-English translation errors that were detected by students for each MT system and their linguistic types. In addition, the table includes the percentage of students who were able to identify the same type of error.

Table 2. Students' error analysis of Arabic-English MT

\begin{tabular}{llll}
\hline MT System & Error & Type of Error & Students' Identification of Errors (\%) \\
\hline Systran & historian and the famous Arab sociologist & grammatical & $78.6 \%$ \\
& owner & lexical & $93 \%$ \\
& villagers & lexical & $78.6 \%$ \\
& missing of "its" & grammatical & $93 \%$ \\
& the & grammatical & $93 \%$ \\
& things distinguish it is proud of & grammatical & $100 \%$ \\
& owner & lexical & $93 \%$ \\
& meeting & lexical & $93 \%$ \\
& provided & lexical & $93 \%$ \\
& villagers & lexical & $78.6 \%$ \\
& oldest universities & grammatical & $21.5 \%$ \\
& missing of "its" & grammatical & $93 \%$ \\
& classrooms & lexical & $78.6 \%$ \\
& witnesses various celebrations of various festivals and & grammatical & $85.7 \%$ \\
classrooms & & \\
\hline & owner & lexical & $93 \%$ \\
\hline
\end{tabular}

It is noticeable that Babylon has made the biggest number of grammatical and lexical errors among the three systems and Google Translate has the fewest number of errors and thus it was chosen by the participants in the study as the best of the three MT systems in Arabic-English translation mode.

Figure 2 compares between the three MT systems with regard to the frequency of errors that were identified by the students in Arabic-English translation as shown in Table 2. The errors listed in the table are fifteen errors, where Systran made four errors out of the total fifteen (26.66\%), Babylon made ten (66.66\%) and Google Translate made only one error, which is less than $1 \%$. Notably, in the examples discussed in this mode of Arabic-English translation there is not much difference between the frequency of lexical and grammatical errors where the lexical errors are eight out of fifteen errors and the grammatical errors are seven out of fifteen errors. 


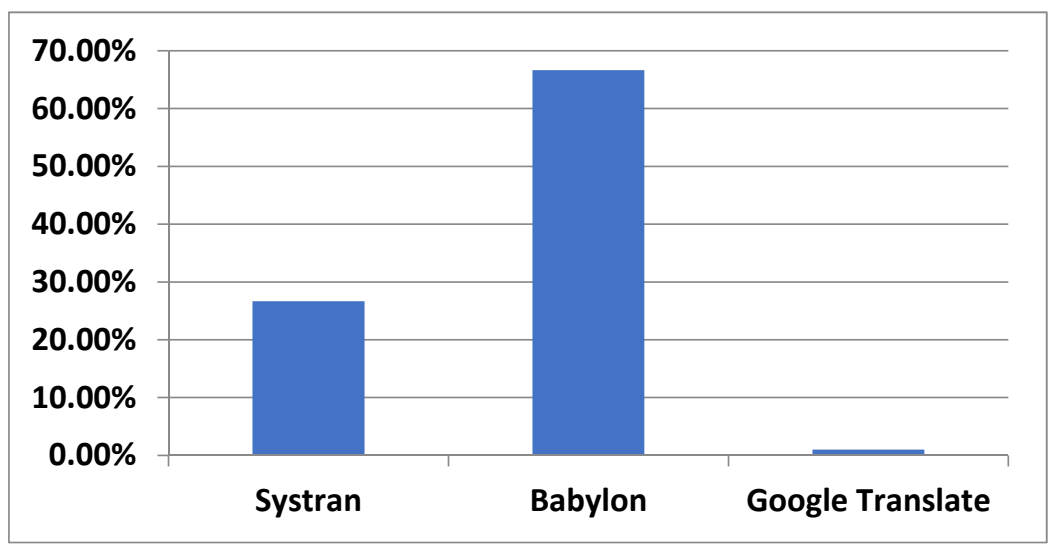

Figure 2. Comparison of frequency of errors in the three MT systems for Arabic-English translation

As Figure 2 shows, Google Translate has the fewest number of errors and thus produces the best MT output followed by Systran and then Babylon that has the biggest number of errors and thus shows the poorest performance.

Looking at all the errors identified by the students in the examples given in both directions of translation (English into Arabic and Arabic into English), it turns out that the number of errors identified by all the students in the three MT outputs is fewer in English-Arabic translation than Arabic-English translation. Irrespective of Google Translate which made only one error in each direction of translation in the examples discussed, the other two systems made more errors in the mode of Arabic-English translation than the other way around. In fact, Google Translate made only one error in each direction. However, since the other two systems made more errors in the mode of Arabic-English translation, the frequency of errors in Google Translate is very small (less than 1\%) compared to the other direction (English-Arabic). It is thus made clear that Arabic-English translation is more challenging for MT systems. This can be due to the complex nature of Arabic morphology and syntax, as pointed out by Sabtan $(2018,2019)$.

In fact, the students' identification of the MT errors in Arabic/English/Arabic translation helps them to better understand the linguistic differences between the SL and TL in the English-Arabic language pair. They also managed to know the different types of translation problems facing MT and this consequently leads them to overcome such problems by giving a better human translation. This is consistent with what has been suggested by Somers (2001) that MT can be used in foreign language learning and teaching and thus can be used as a computer-assisted language learning (CALL) tool. In particular, Gaspari (2002) argues about the benefits of using online MT services in MT classes. However, in the current study the author agrees with Clifford et al. (2013) and Alsalem (2019) that the use of online MT is more beneficial in higher-level courses. Thus, following the analysis in this section, the research questions raised in section three have been answered.

\section{Conclusion}

The present study has aimed at shedding light on the teaching of an MT course to EFL student translators in an Omani university. It discussed the theoretical and practical parts of the course content. The theoretical part focused on a number of topics covering various areas in MT. As for the practical part, students were given assignments to post-edit the MT output of three MT systems (Google Translate, Systran and Babylon) for the English-Arabic language pair and were asked to identify the types of errors in each MT system and choose the best one that has the fewest number of errors. The results show that the students, with varying degrees of success, managed to spot some linguistic errors with the MT output for each MT system. This identification of errors by students help them to focus on the differences between the SL and TL as far as English and Arabic are concerned. This, in turn, can be beneficial to their EFL learning and translation training. The pedagogical reasoning behind this is expressed by Somers (2001), as he maintains that subjecting MT output to post-editing by the students causes them to focus on the differences between the SL and TL and identify the processes by which a given meaning in the SL is conveyed to the TL. Accordingly, students were able to spot MT errors in each one of the three systems under investigation and classify such errors into lexical and grammatical errors. They chose Google Translate as the best system among the three MT systems and finally produced a better human translation that is intelligible and acceptable.

It should be noted that the results of the current study are limited to the test of two texts (one of which is Arabic 
and the other is English) on three MT systems. Also, the sample of the present study is too small to be generalized as it involves only fifteen translation students. However, despite these limitations it can be argued that the results of the students' analysis of MT output show that EFL translation students can benefit from being exposed to free online MT. However, it should be noted that post-editing of MT output is beneficial to translation students' training at an advanced stage of their study but students at the beginning stage of their study should not rely heavily on MT since, as stated by Alsalem (2019), this would reduce their interest in searching for equivalents so as to learn properly.

The author concludes that there is a need to incorporate MT courses in translation departments in the Arab world. Moreover, the paper argues that integrating the online translation services into MT courses can be beneficial to students majoring in translation. This can significantly contribute to enhancing their language and translation skills.

Based on the results reported in the present study, a number of suggestions for further research are proposed as follows. First, other studies could be conducted to explore the EFL students' use of MT technology in other EFL activities such as vocabulary, reading and writing. Second, research could be carried out on discussing the teaching of other translation technologies such as CAT tools. Third, research is needed to explore the instructors' use and perceptions of free online MT systems and their attitudes towards the use of these systems. Finally, there could be a study on investigating the use of translation technologies including MT and CAT tools by Arab professional translators.

\section{References}

Alhaisoni, E., \& Alhaysony, M. (2017). An Investigation of Saudi EFL University Students' Attitudes towards the Use of Google Translate. International Journal of English Language Education, 5(1), 72-82. https://doi.org/10.5296/ijele.v5il.10696

Allen, J. (2003). Post-editing. In H. Somers (Ed.), Computers and Translation: A translator's guide (pp. 297-317). Amsterdam, Philadelphia: John Benjamins Publishing Company. https://doi.org/10.1075/btl.35.19all

Almutawa, F., \& Izwaini, S. (2015). Machine Translation in the Arab World: Saudi Arabia as a Case Study. Trans-Kom, Journal of Translation and Technical Communication Research, 8(2), 382-414.

Alqudsi, A., Omar, N., \& Shaker, K. (2014). Arabic Machine Translation: A Survey. Artificial Intelligence Review, 42(4), 549-572. https://doi.org/10.1007/s10462-012-9351-1

Alsalem, R. (2019). The Effects of the Use of Google Translate on Translation Students' Learning Outcomes. AWEJ for Translation \& Literary Studies, 3(4), 46-60. https://doi.org/10.24093/awejtls/vol3no4.5

Anderson, D. D. (1995). Machine Translation as a Tool in Second Language Learning. CALICO Journal, 13(1), 68-97.

Anggrina, B., Pramudita, K. E., \& Suparmi, S. (2017). EFL Learners'Post-editing on Google English-Indonesian Translation Output (pp. 130-137). In Proceedings of the Fifth International Seminar on English Language and Teaching (ISELT-5).

Arnold, D., Balkan, L., Meijer, S., Humphreys, R. L., \& Sadler, L. (1994). Machine Translation: An Introductory Guide. Blackwell Publishers, 238 Main St. Cambridge, Mass. 02142. Blackwells-NCC, London.

Bakaric, B. (2019). Teaching Computer-assisted Translation: A Proposal for Course Content (pp. 996-1001). In 42nd International Convention on Information and Communication Technology, Electronics and Microelectronics (MIPRO), https://doi.org/10.23919/MIPRO.2019.8756692

Belam, J. (2002). Teaching Machine Translation Evaluation by Assessed Project Work (pp. 131-136). In 6th EAMT Workshop on Teaching Machine Translation, Manchester.

Clavier, V., \& Poudat, C. (2001). Teaching Machine Translation in non-Computer Science Subjects: Reports of An Educational Experience within the University of Orleans (pp. 19-23). In MT Summit VIII Workshop on Teaching Machine Translation, Santiago de Compostela.

Clifford, J., Merschel, L., \& Munné, J. (2013). Surveying the Landscape: What Is the Role of Machine Translation in Language Learning? Revista d'innovació Educativa, 10, 108-121. https://doi.org/10.7203/attic.10.2228

Crego, J., Kim, J., Klein, G., Rebollo, A., Yang, K., Senellart, J., ... Zoldan, P. (2016). Systran's Pure Neural Machine Translation Systems. arXiv preprint arXiv:1610.05540.

Dickins, J., Hervey, J., \& Higgins, I. (2002). Thinking Arabic Translation: A Course in Translation Method: Arabic to English. London, New York: Routledge. 
Forcada, M. L. (2017). Making sense of neural machine translation. Translation Spaces, 6(2), 291-309. https://doi.org/10.1075/ts.6.2.06for

Garcia, I. (2011). Translating by post-editing: is it the way forward? Machine Translation, 25(3), 217-237. https://doi.org/10.1007/s10590-011-9115-8

Gaspari, F. (2001). Teaching Machine Translation to Trainee Translators: A Survey of their Knowledge and Opinions (pp. 35-44). In MT Summit VIII Workshop on Teaching Machine Translation, Santiago de Compostela.

Gaspari, F. (2002). Using Free On-line Services in MT Teaching (pp. 145-153). In Proceedings of the 6th EAMT Workshop on Teaching Machine Translation, Manchester.

Hutchins, W. (1986). Machine Translation: Past, Present, Future. Chichester, Ellis Horwood Limited.

Hutchins, W., \& Somers, H. (1992). An Introduction to Machine Translation. London: Academic Press.

Izwaini, S. (2006). Problems of Arabic Machine Translation: Evaluation of Three Systems (pp. 118-148). In The Challenge of Arabic for NLP/MT Conference, The British Computer Society, London, UK.

Jabak, O. O. (2019). Assessment of Arabic-English translation produced by Google Translate. International Journal of Linguistics, Literature and Translation, 2(4), 238-247.

Jimenez-Cresp, M. A. (2017). The role of translation technologies in Spanish language learning. Journal of Spanish Language Teaching, 4(2), 181-193. https://doi.org/10.1080/23247797.2017.1408949

Johnson, M., Schuster, M., Le, Q. V., Krikun, M., Wu, Y., Chen, Z., ... Dean, J. (2017). Google's Multilingual Neural Machine Translation System: Enabling Zero-Shot Translation. Transactions of the Association for Computational Linguistics, 5, 339-351. https://doi.org/10.1162/tacl_a_00065

Jolley, J. R., \& Maimone, L. (2015). Free Online Machine Translation: Use and Perceptions by Spanish Students and Instructors. In A. J. Moeller (Ed.), Learn languages, Explore Cultures, Transform Lives (pp. 181-200). Minneapolis: 2015 Central States Conference on the Teaching of Foreign Languages.

Jurafsky, D., \& Martin, J. H. (2009). Speech and Language Processing: An Introduction to Natural Language Processing, Computational Linguistics, and Speech Recognition. Upper Saddle River, NJ: Pearson/Prentice Hall.

Kenny, D., \& Way, A. (2001). Teaching Machine Translation \& Translation Technology: A Contrastive Study (pp. 13-17). In MT Summit VIII Workshop on Teaching Machine Translation, Santiago de Compostela.

Koponen, M. (2015). How to teach machine translation post-editing? Experiences from a post-editing course (pp. 2-15). In Proceedings of the 4th workshop on post-editing technology and practice, Miami, USA.

Koponen, M. (2016). Is machine translation post-editing worth the effort? A survey of research into post-editing and effort. The Journal of Specialised Translation, 25, 131-148.

Mitamura, T., Nyberg, E., \& Frederking, R. (2003). Teaching Machine Translation in a Graduate Language Technologies Program. In Proceedings of Machine Translation Summit IX, New Orleans, USA.

Niño, A. (2009). Machine translation in foreign language learning: language learners' and tutors' perceptions of its advantages and disadvantages. ReCALL, 21(2), 241-258. https://doi.org/10.1017/S0958344009000172

O’Brien, S. (2002). Teaching Post-Editing: A Proposal for Course Content (pp. 99-106). In 6th EAMT Workshop on Teaching Machine Translation, Manchester.

Okpor, M. D. (2014). Machine Translation Approaches: Issues and Challenges. IJCSI International Journal of Computer Science Issues, 11(5), 159-165.

Ryding, K. C. (2005). A Reference Grammar of Modern Standard Arabic. Cambridge: Cambridge University Press. https://doi.org/10.1017/CBO9780511486975

Sabtan, Y. M. (2016). Bilingual Lexicon Extraction from Arabic-English Parallel Corpora with a View to Machine Translation. Arab World English Journal (AWEJ) Special Issue on Translation, 5, 317-336. https://doi.org/10.2139/ssrn.2795900

Sabtan, Y. M. (2018). Towards Corpus-Based Stemming for Arabic Texts. International Journal of Linguistics, Literature and Translation, 1(4), 119-129.

Sabtan, Y. M. (2019). Investigating the Effect of Stemming and Part-of-Speech Tagging on Automatic Extraction of Translation Equivalents from Parallel Corpora for Arabic-English Machine Translation. In S. Faiq (Ed.), 
Arabic Translation Across Discourses (pp. 197-211). London, New York: Routledge. https://doi.org/10.4324/9781351063388-14

Somers, H. (2001). Three Perspectives on MT in the Classroom (pp. 25-29). In MT Summit VIII Workshop on Teaching Machine Translation, Santiago de Compostela.

Somers, H. (2003). Machine translation: latest developments. In R. Mitkov (Ed.), The Oxford Handbook of Computational Linguistics (pp. 512-528), Oxford: Oxford University Press.

Somers, H., \& Diaz, G. F. (2004). Translation Memory vs. Example-based MT: What is the difference? International Journal of Translation, 16(2), 5-33.

Somers, H., \& Wild, E. (2000). Evaluating Machine Translation: The Cloze Procedure Revisited. In Translating and the Computer 22: Proceedings of the Twenty-second International Conference on Translating and the Computer, London.

Stymne, S., \& Ahrenberg, L. (2012). On the practice of error analysis for machine translation evaluation (pp. 1785-1790). In Proceedings of LREC 2012.

Trujillo, A. (1999). Translation Engines: Techniques for Machine Translation. London: Springer. https://doi.org/10.1007/978-1-4471-0587-9

White, J. S. (2003). How to evaluate machine translation. In H. Somers (Ed.), Computers and Translation: A translator's guide (pp. 211-244). Amsterdam, Philadelphia: John Benjamins Publishing Company. https://doi.org/10.1075/btl.35.16whi

Wu, Y., Schuster, M., Chen, Z., Le, Q. V., Norouzi, M., Macherey, W., ... Dean, J. (2016). Google's Neural Machine Translation System: Bridging the Gap between Human and Machine Translation. arXiv preprint arXiv:1609.08144, 2016.

\section{Notes}

Note 1. https://translate.google.com

Note 2. https://translation.babylon-software.com

Note 3. https://translate.systran.net/translationTools/text

Note 4. http://translatorsavenue.com

\section{Copyrights}

Copyright for this article is retained by the author, with first publication rights granted to the journal.

This is an open-access article distributed under the terms and conditions of the Creative Commons Attribution license (http://creativecommons.org/licenses/by/4.0/). 